\title{
Viral haemorrhagic fever
}

\author{
Authors: Caoimhe Nic Fhogartaigh ${ }^{A}$ and Emma Aarons ${ }^{B}$
}

Viral haemorrhagic fevers (VHF) are a range of viral infections with potential to cause life-threatening illness in humans. Apart from Crimean-Congo haemorrhagic fever (CCHF), they are largely confined to Africa, distribution being dependent on the ecology of reservoir hosts. At present, the largest ever epidemic of Ebola virus disease (EVD or Ebola) is occurring in West Africa, raising the possibility that cases could be imported into non-endemic countries. Diagnosis and management is challenging due to the non-specificity of early symptoms, limited laboratory facilities in endemic areas, severity of disease, lack of effective therapy, strict infection control requirements and propensity to cause epidemics with secondary cases in healthcare workers.

\section{Virology and epidemiology}

Ebolaviruses and marburgviruses are filoviruses: filamentous, enveloped virions with RNA-encoded genomes. Ebola was discovered during simultaneous outbreaks of febrile illness with shock and haemorrhage in Sudan and former Zaire in 1976. ${ }^{1}$ Five species of ebolavirus exist, associated with varying degrees of virulence. Viruses of three species cause human outbreaks: Ebola virus (EBOV, formerly Zaire ebolavirus), Sudan virus and Bundibugyo virus. EBOV is responsible for the current and largest ever epidemic, and the first description of EVD in West Africa. Countries which have experienced EVD outbreaks are illustrated in Fig 1. Marburg virus (MARV) was initially isolated in 1967 from handlers of African green monkeys in Marburg, Germany who suffered a fatal illness. ${ }^{3}$ Since then cases have been seen in Zimbabwe, Uganda, Democratic Republic of Congo, Kenya and Angola (Fig 1). These filoviruses tend to cause outbreaks with high mortality which can usually be traced back to an index human or animal infection. There is accumulating molecular and serological evidence that fruit bats are reservoirs and that human infection is acquired through contact with their body fluids. Modes of transmission and risk factors are outlined in Table 1.

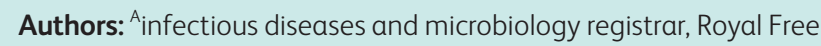
Hospital, London, UK; ${ }^{\mathrm{B}}$ consultant virologist and infectious diseases physician, Rare and Imported Pathogens Laboratory, PHE Porton, Salisbury, UK
Lassa virus is an arenavirus. The virions are pleiomorphic and enveloped with RNA-encoded, segmented genomes. There are four lineages, but a high degree of strain variation exists. The infection was first described in 1969 following cases in Lassa, North Nigeria. ${ }^{4}$ Disease is widely endemic in West Africa where 100,000-500,000 cases per year are estimated, ${ }^{5}$ mainly in Sierra Leone, Liberia, Guinea, and Nigeria (Fig 2), but is predicted to occur in other West African countries. ${ }^{6}$ The natural reservoir is the multimammate rat, which inhabits rural homes and fields. Infection occurs through inhalation of dust contaminated with infected rat urine, or close contact with rodents or human cases. Sporadic cases, rather than epidemics, are seen.

CCHF virus is a bunyavirus of the genus Nairovirus. The virions are spherical and enveloped with segmented RNA genomes. CCHF virus displays the greatest degree of sequence diversity of any arbovirus. ${ }^{7}$ It is carried by the Hyalomma spp tick, widely distributed throughout Africa, Asia, the Middle East and Eastern Europe (Fig 3). Countries with confirmed cases are listed in Table 1. Reservoirs of infection include cattle, sheep, goats and rodents. Infection may be acquired through an infected tick bite, crushing a tick or removing a tick with one's bare hands, or through contact with body fluids of infected animals. Secondary cases have occurred in family members, and in parts of Eastern Europe - Turkey and Iran in particular - farming-related outbreaks affect hundreds of people annually. ${ }^{7,8}$ The incubation period is shorter than other VHFs (Table 1).

\section{Pathogenesis}

Detailed understanding of the pathogenic mechanisms of VHFs is lacking. Key viral target cells include monocytes, macrophages, dendritic cells and vascular endothelial cells, which once infected enable dissemination through lymphatics to other organs. ${ }^{9}$ In EVD, research has demonstrated that a viral protein, VP35, inhibits interferon (IFN)-regulatory factor 3 necessary for the induction of IFN $\alpha / \beta$ and antiviral immune responses. ${ }^{9}$ Extensive cytokine activation and release of tissue factor lead to endothelial damage, oedema, coagulopathy, shock, tissue necrosis and multiorgan failure.

\section{Clinical features}

VHFs have similarities in their clinical presentations. However, high rates of asymptomatic and subclinical infections are seen with Lassa, in contrast to filovirus infections which are 


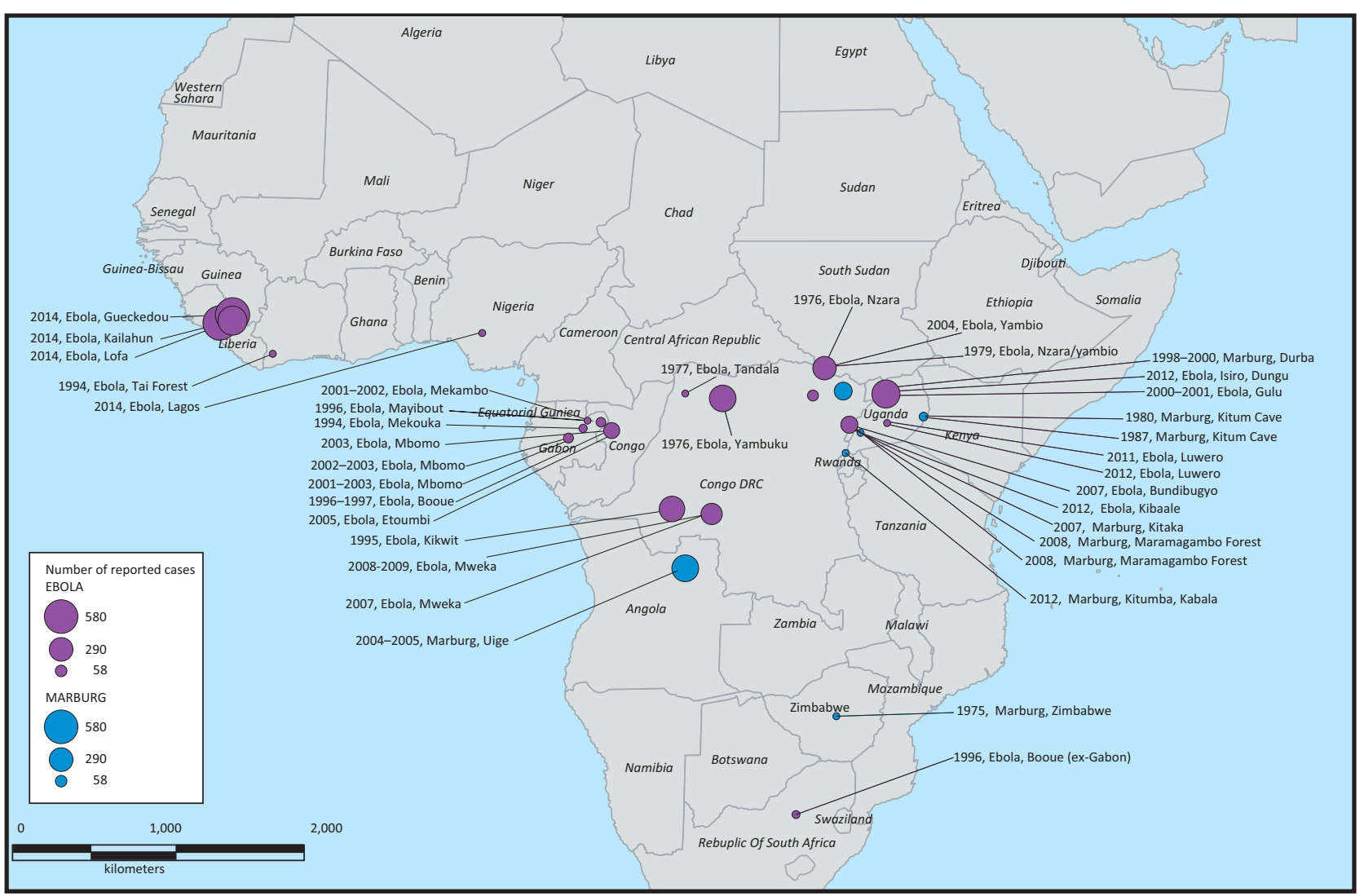

Fig 1. Geographical distribution of Ebola and Marburg. This map includes all cases and outbreaks of Ebola or Marburg documented to 26 August 2014 . (c) Crown copyright. Reproduced with permission of Public Health England. ${ }^{2}$

\section{Key points}

Clinical presentation can be very non-specific. Therefore, careful travel history, including timing, regions and exposures, is crucial for the identification (and exclusion) of possible cases.

The Advisory Committee for Dangerous Pathogens' viral haemorrhagic fever (VHF) risk assessment algorithm is designed to aid early diagnosis of VHF. Consequently, "highly possibility of VHF' does not equate to high probability of VHF. In the absence of a specific relevant epidemiological exposure, an alternative diagnosis is considerably more likely.

'High possibility' cases should be isolated in a single room and appropriate personal protective equipment worn during contact; double gloves, fluid repellent disposable coverall or gown, full length plastic apron (over the coverall/gown), head cover eg surgical cap, fluid repellent footwear eg surgical boots, full face shield or goggles, and fluid repellent FFP3 respirator.

Malaria testing performed locally is an urgent priority.

Consultation with local infection specialists must take place before the Imported Fever Service is contacted for discussion of VHF testing.

KEYWORDS: Viral haemorrhagic fever, Ebola, Marburg, Crimean-Congo haemorrhagic fever, Lassa, personal protective equipment predominantly symptomatic with significant mortality. In hyperendemic areas, subclinical CCHF virus infections may occur relatively frequently. ${ }^{7}$

In general, three phases of illness are seen: a generalisation phase (week 1), early organ phase (week 2), and late organ or convalescent phase (week 3). ${ }^{7-11}$ The generalisation phase is characterised by non-specific symptoms of fever, chills, myalgia, malaise, headache, gastrointestinal symptoms and frequently, sore throat. Severe watery diarrhoea is a common clinical feature in the current EBOV outbreak. Cough and chest pain may also occur. The onset is more abrupt with EVD, MARV infection and CCHF. Conjunctivitis and maculopapular rash may be seen, but in many cases the examination is normal and the patient may not appear very unwell. During the early organ phase the complications of endothelial damage manifest as petechiae, ecchymoses, conjunctival injection, oedema, mucosal haemorrhage, bloody diarrhoea, melaena, haematemesis, dyspnoea due to pulmonary oedema and irritability. In the late organ stage, illness may progress to disseminated intravascular coagulation, shock, liver and renal dysfunction, seizures, coma and death. ${ }^{7-11}$ CCHF tends to run a shorter course with appearance of haemorrhagic features around days $3-5$ in most cases. However, haemorrhagic features may not always be seen with other VHFs. ${ }^{8}$ Those who recover, defervesce, but may run a protracted convalescent course with sequelae such as arthralgia, hepatitis, orchitis, transverse myelitis, hearing loss, visual impairment, psychological disturbance and social isolation., ${ }^{9,11}$ 
Table 1. Viral haemorrhagic fevers. ${ }^{7-11,13,14}$

\begin{tabular}{|c|c|c|c|}
\hline Parameter & EBOV/MARV & Lassa & $\mathrm{CCHF}$ \\
\hline Reservoir host & Fruit bats & Multimammate rat Mastomys natalensis & $\begin{array}{l}\text { Cattle, sheep, goats and small } \\
\text { mammals, including rodents }\end{array}$ \\
\hline Vector & - & - & Hyalomma spp tick \\
\hline $\begin{array}{l}\text { Mode of } \\
\text { transmission }\end{array}$ & $\begin{array}{l}\text { Close contact with blood/body } \\
\text { fluids of infected animal or } \\
\text { human; inoculation injury; } \\
\text { exposure to viral cultures }\end{array}$ & $\begin{array}{l}\text { Inhalation of dust particles contaminated } \\
\text { with infected rats' urine; close contact } \\
\text { with blood/body fluids of infected animal } \\
\text { or human; inoculation injury; exposure to } \\
\text { viral cultures }\end{array}$ & $\begin{array}{l}\text { Bite of infected tick; close contact with } \\
\text { blood/body fluids of infected animal } \\
\text { or human; inoculation injury; exposure } \\
\text { to viral cultures }\end{array}$ \\
\hline Risk factors & $\begin{array}{l}\text { Preparation and consumption of } \\
\text { bush meat; handling/butchering } \\
\text { dead primates (Ebola); exposure } \\
\text { to Rousettus fruit bat excreta in } \\
\text { caves/mines (MARV); caring for a } \\
\text { suspected/known case; physical } \\
\text { contact during funeral ceremony } \\
\text { of one who died of fever in an } \\
\text { endemic area; HCW exposed to } \\
\text { blood/body fluid of suspected/ } \\
\text { known case; laboratory exposure }\end{array}$ & $\begin{array}{l}\text { Basic living, camping, hiking or } \\
\text { motorcycling in endemic areas; sweeping/ } \\
\text { cleaning dust contaminated with rat urine } \\
\text { or faeces; eating food contaminated by } \\
\text { rats; handling, preparing or eating rats; } \\
\text { caring for a suspected/known case; } \\
\text { physical contact during funeral ceremony } \\
\text { of one who died of fever in an endemic } \\
\text { area; HCW exposed to blood/body fluid } \\
\text { of suspected/known case; laboratory } \\
\text { exposure }\end{array}$ & $\begin{array}{l}\text { Sustaining a tick bite in an endemic } \\
\text { area; removing tick(s) from self or } \\
\text { animal in an endemic area; farming in } \\
\text { an endemic area; caring for a } \\
\text { suspected/known case; physical } \\
\text { contact during funeral ceremony of } \\
\text { one who died of fever in an endemic } \\
\text { area; HCW exposed to blood/body } \\
\text { fluid of suspected/known case; } \\
\text { laboratory exposure }\end{array}$ \\
\hline $\begin{array}{l}\text { Incubation } \\
\text { period }\end{array}$ & $5-10$ days (range $2-21$ ) & 3-10 days (maximum 18) & $\begin{array}{l}\text { 1-5 days (maximum 9) via tick bite; } \\
5-7 \text { days (maximum 13) via blood } \\
\text { exposure }\end{array}$ \\
\hline $\begin{array}{l}\text { Poor } \\
\text { prognostic } \\
\text { features }\end{array}$ & $\begin{array}{l}\text { Age }>40 \text { years; renal failure; DIC; } \\
\text { AST } \geq 400 \mathrm{U} / \text {; viral load } \geq 10^{8} \\
\text { copies } / \mathrm{ml}\end{array}$ & $\begin{array}{l}\text { Haemorrhage; transaminases }>400 \mathrm{IU} / \mathrm{l} \text {; } \\
\uparrow \mathrm{LDH} \text {; viral load } \geq 10^{7} \text { copies } / \mathrm{ml} \text {; no } \\
\text { antibody response by day } 8-10\end{array}$ & $\begin{array}{l}\text { WBC }>10,000 / \mathrm{mm}^{3} ; \text { platelets } \\
<20 \times 10^{3} / \mathrm{mm} 3 ; \text { AST > } 200 \mathrm{U} / \mathrm{l} ; \text { ALT } \\
>150 \mathrm{U} / \text {; APTT }>60 \text { secs; fibrinogen } \\
<110 \mathrm{mg} / \mathrm{dl} \text {; viral load } \geq 10^{8} \text { copies } / \mathrm{ml}\end{array}$ \\
\hline Treatment & Supportive & Ribavirin (early) & Supportive $+/$ - ribavirin \\
\hline $\begin{array}{l}\text { Case fatality } \\
\text { ratio }\end{array}$ & $\begin{array}{l}\text { EBOV } 60-90 \% \text {; Sudan virus } \\
50-70 \% \text {; Bundibugyo virus } 25 \% \text {; } \\
\text { MARV } 25-85 \%\end{array}$ & $15 \%$ of hospitalised cases & $5 \%$ of hospitalised cases \\
\hline
\end{tabular}

ALT = alanine transaminase; $\mathrm{APTT}=$ activated partial thromboplastin time; $\mathrm{AST}=$ aspartate transaminase; $\mathrm{CCHF}=\mathrm{Crimean}-\mathrm{Congo}$ hemorrhagic fever; $\mathrm{DIC}=$ disseminated intravascular coagulation; $\mathrm{EBOV}=$ Ebola virus: $\mathrm{HCW}=$ healthcare worker; $\mathrm{LDH}=$ lactate dehydrogenase; $M A R V=M a r b u r g$ virus; WBC = white blood cells.

Case fatality rates (CFR) vary between the causative infections (Table 1). The current EBOV outbreak has been reported to have a CFR of $58-70 \%$, compared with $90 \%$ in previous outbreaks. ${ }^{12}$ This may reflect improvements in early detection and supportive care but there is probably significant underascertainment of undiagnosed fatal cases.

\section{Risk assessment}

The Advisory Committee for Dangerous Pathogens (ACDP) has published guidance on risk assessment of patients with potential VHF in the form of an assessment algorithm. ${ }^{15}$ If there is any uncertainty about whether the patient should be designated as 'low possibility of VHF' or 'high possibility of VHF', the case should be discussed with a local infection specialist. Note that 'high possibility' does not equate to high probability; on the contrary, if there has been no contact with any sick or dead person, nor any other exposure relevant to the geographically-pertinent $\operatorname{VHF}(\mathrm{s})$, then an alternative diagnosis is considerably more likely.

\section{Transmission of infection from person-to-person}

Person-to-person spread occurs through mucous membrane or percutaneous contact with body fluids (blood, urine, faeces or saliva) of an infected human. More severely ill cases have higher viral loads and are more likely to cause onward transmission. Skin and skin structures appear to be heavily infected after death and may transmit infection during burial practices. In close household contacts, 3-17\% secondary attack rates have been documented. ${ }^{16,17}$ In the healthcare setting, needlestick injuries are a very efficient mode of transmission and have been associated with greater mortality. ${ }^{17}$ There is no scientific or epidemiological evidence of filovirus transmission via the airborne route. Sexual transmission in convalescent cases due to prolonged viral shedding in semen is a relatively minor mode of transmission. ${ }^{9,10}$

\section{Diagnosis}

Leucopenia, thrombocytopenia and transaminitis (aspartate transaminase (AST) $>$ alanine transaminase (ALT)) are suggestive of VHF in a patient with a compatible clinical history 


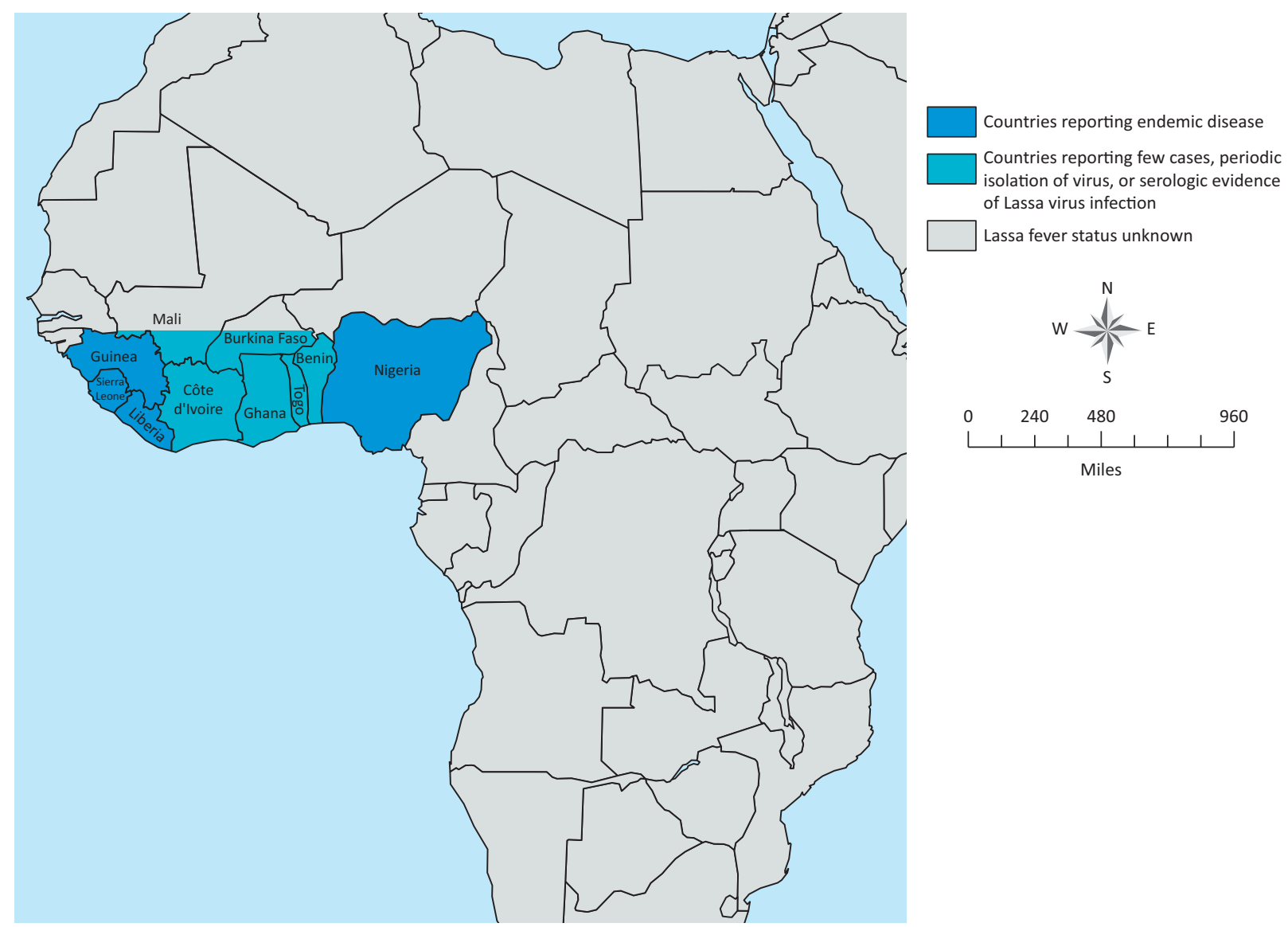

Fig 2. Geographical distribution of Lassa fever. Reproduced with permission of CDC.

and within 21 days of a credible epidemiological exposure, particularly where the malaria film is negative. New ACDP guidance $^{13}$ recommends that such investigations should be performed urgently in the local laboratory, and provided standard precautions (and additional splash precautions where necessary) are adhered to, it is safe to do so. Viraemia occurs from day 1 of fever, and persists throughout illness. IgM and IgG appear from around days 3 and 7 respectively, but delay in antibody production may occur and is associated with a poorer prognosis. ${ }^{7,11,13}$ Laboratory diagnosis is made by reversetranscription polymerase chain reaction (PCR) which is highly sensitive and specific and can be performed on blood, urine and saliva/throat swabs. Testing is arranged by communication between local infection specialists and the Imported Fever Service, based at the Rare and Imported Pathogens Laboratory, Salisbury. Serological tests are not routinely performed in the $\mathrm{UK}$ at present. Viral culture is only performed in containment level 4 laboratories for epidemiological or research purposes.

\section{Infection control}

Suspected cases should be isolated in a single room with ensuite bathroom (or dedicated commode) and clinical waste bin. When initially assessing a potential case, for example a febrile $\left(\geq 37.5^{\circ} \mathrm{C}\right)$ patient with a recent history of travel to a country in which VHF is currently present, contact precautions with gloves, apron and hand hygiene are required.
If epidemiological risk is confirmed such that the patient is designated as 'high possibility of VHF' then the following additional items of personal protective equipment (PPE) should also be worn as indicated in the ACDP guidance:
$>$ double gloves
> fluid repellent disposable coverall or gown
$>$ full length plastic apron (over the coverall/gown)
$>$ head cover eg surgical cap
$>$ fluid repellent footwear eg surgical boots
$>$ full face shield or goggles
$>$ fluid repellent FFP3 respirator.

Removal of PPE and hand hygiene must be performed with meticulous care in order to avoid potential self-contamination. Staff caring for the patient should be kept to a minimum. Once the results of VHF testing are available, infection control measures should be reviewed. In the event that a VHF diagnosis is confirmed by laboratory testing, transfer to the Royal Free High Level Isolation Unit is advised. ${ }^{15}$

\section{Treatment}

Early diagnosis, supportive therapy (fluid resuscitation, and correction of electrolyte and coagulation abnormalities) and treatment of secondary infections improve outcomes. ${ }^{9,13}$ For Lassa fever there is evidence that ribavirin, if given within the first 7 days of fever, reduces mortality, ${ }^{18}$ but its efficacy in CCHF 


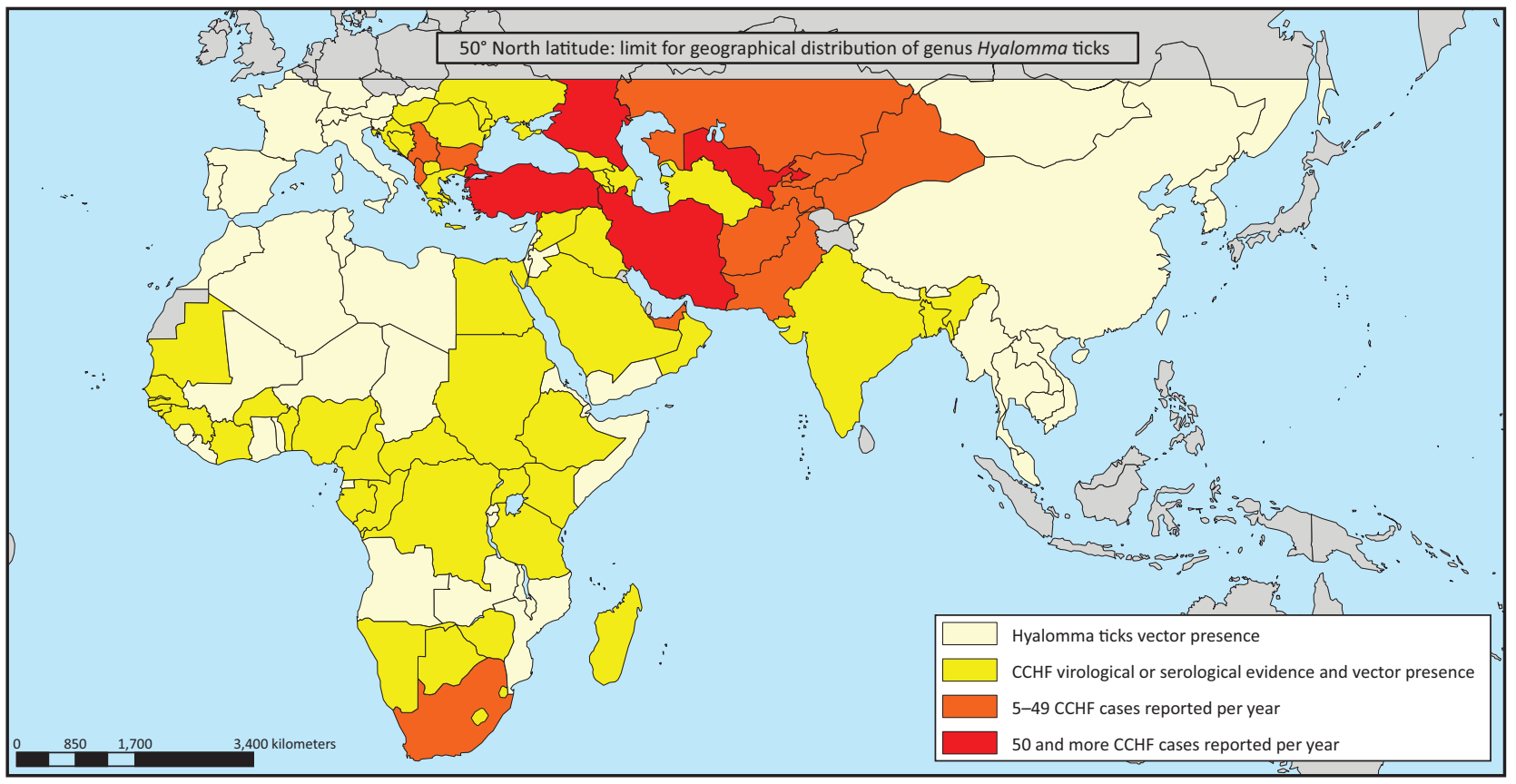

Fig 3. Geographical distribution of Crimean-Congo haemorrhagic fever. Reproduced with permission of the WHO.

is uncertain, ${ }^{6,19}$ and it is not effective in filovirus infection. An experimental treatment combining three neutralising monoclonal antibodies against an EBOV protein, has demonstrated some efficacy in non-human primate models, ${ }^{20}$ and has been used recently on a compassionate basis to treat seven infected human cases, five of whom survived.

\section{Outbreak control}

Early recognition and isolation of cases, meticulously strict infection control and waste management, careful handling of the dead during burials, and contact tracing are all crucial elements in epidemic control. Challenges in outbreak control are exacerbated by fear and misunderstanding in local populations as epidemics wipe out communities. Therefore, culturally sensitive education and support through local leaders is essential.

\section{Prevention}

Prevention is largely through avoidance of risky exposures, such as consumption of bush meat, tick bites, or close contact with a suspected case without appropriate PPE. In the event of an exposure, management and follow up should be co-ordinated by an infection specialist, and post-exposure prophylaxis with ribavirin may be considered for Lassa or CCHF high-risk contacts. Development of vaccines is hampered by the degree of strain variation seen with these viruses. Nonetheless, a few Ebola vaccine candidates are in phase 1 trials.

\section{References}

1 Brès P. The epidemic of Ebola haemorrhagic fever in Sudan and Zaire, 1976 (introductory note). Bull World Health Organ 1978;56:245.
2 Public Health England. Ebola and Marburg haemorrhagic fevers: outbreaks and case locations. Available online at www.gov.uk/ebolaand-marburg-haemorrhagic-fevers-outbreaks-and-case-locations [Accessed 17 November 2014].

3 Bonin O. The Cercopithecus monkey disease in Marburg and Frankfurt (Main), 1967. Acta Zool Pathol Antverp 1969;48:319-31.

4 Monath TP. Lassa fever: review of epidemiology and epizootiology. Bull World Health Organ 1975;52:577-92.

5 Ogbu O, Ajuluchukwu E, Uneke CJ. Lassa fever in West African sub-region: an overview. J Vector Borne Dis 2007;44:1-11.

6 Fichet-Calvet E and Rogers DJ. Risk maps of Lassa fever in West Africa. PLoS Negl Trop Dis 2009;3:e388.

7 Bente DA, Forrester NL, Watts DM et al. Crimean-Congo hemorrhagic fever: History, epidemiology, pathogenesis, clinical syndrome and genetic diversity. Antiviral Res 2013;100:159-89.

8 Bannister B. Viral haemorrhagic fevers imported into non-endemic countries: risk assessment and management. Br Med Bull 2010;95:193-225.

9 Feldmann H and Geisbert TW. Ebola Haemorrhagic Fever. Lancet 2011;377:849-62.

10 Bah EI, Lamah MC, Fletcher T et al. Clinical presentation of patients with ebola virus disease in Conakry, Guinea. N Engl J Med 2014 , in print.

11 Mehedi M, Groseth A, Feldmann H, Ebihara H. Clinical aspects of Marburg hemorrhagic fever. Future Virol 2011;6:1091-106.

12 WHO (2014). Ebola response roadmap - Situation report update. Global Alert and Response, 17 December 2014. Available online at www.who.int/csr/disease/ebola/situation-reports/en/ [Accessed 22 December 2014].

13 Rollin PE, Bausch DG, and Sanchez A. Blood chemistry measurements and D-Dimer levels associated with fatal and nonfatal outcomes in humans infected with Sudan Ebola virus. J Infect Dis 2007;196(Suppl 2):S364-71.

14 Towner JS, Rollin PE, Bausch DG et al. Rapid diagnosis of Ebola haemorrhagic fever by reverse-transcription PCR in an outbreak setting and assessment of patient viral load as a predictor of outcome. J Virol 2004;78:4330-41. 
15 Advisory Committee on Dangerous Pathogens. Management of Hazard Group 4 viral haemorrhagic fevers and similar human infectious diseases of high consequence. November 2014. Available online at www.hpa.org.uk/webc/HPAwebFile/HPAweb_C/ 1194947382005 [Accessed 30 November 2014].

16 WHO. Ebola haemorrhagic fever in Sudan, 1976. Report of a WHO/International Study Team. Bull World Health Organ 1978;56:247-70.

17 WHO. Ebola haemorrhagic fever in Zaire, 1976. Bull World Health Organ 1978;56:271-93.

18 McCormick JB, King IJ, Webb PA et al. Lassa fever. Effective therapy with ribavirin. N Engl J Med 1986;314:20-6.
19 Ascioglu S, Leblebicioglu H, Vahaboglu H, Chan KA. Ribavirin for patients with Crimean-Congo haemorrhagic fever: a systematic review and meta-analysis. J Antimicrob Chemother 2011;66:1215-22.

20 Qiu X, Audet J, Wong G et al. Successful treatment of ebola virusinfected cynomolgus macaques with monoclonal antibodies. Sci Transl Med 2012;4:138.

Address for correspondence: Dr E Aarons, Rare and Imported Pathogens Laboratory, PHE Porton, Salisbury, Wiltshire SP4 0JG, UK.

Email: emma.aarons@phe.gov.uk 